\title{
A Comparative Analysis of Value at Risk Measurement on Emerging Stock Markets: Case of Montenegro
}

\author{
Julija Cerović, Milena Lipovina-Božović, Saša Vujošević \\ University of Montenegro, Faculty of Economics, Podgorica, Montenegro
}

\section{Abstract}

Background: The concept of value at risk gives estimation of the maximum loss of financial position at a given time for a given probability. The motivation for this analysis lies in the desire to devote necessary attention to risks in Montenegro, and to approach to quantifying and managing risk more thoroughly. Objectives: This paper considers adequacy of the most recent approaches for quantifying market risk, especially of methods that are in the basis of extreme value theory, in Montenegrin emerging market before and during the global financial crisis. In particular, the purpose of the paper is to investigate whether extreme value theory outperforms econometric and quantile evaluation of VaR in emerging stock markets such as Montenegrin market. Methods/Approach: Daily return of Montenegrin stock market index MONEX20 is analyzed for the period January, 2004 - February, 2014. Value at Risk results based on GARCH models, quantile estimation and extreme value theory are compared. Results: Results of the empirical analysis show that the assessments of Value at Risk based on extreme value theory outperform econometric and quantile evaluations. Conclusions: It is obvious that econometric evaluations (ARMA(2,0)GARCH $(1,1)$ and RiskMetrics) proved to be on the lower bound of possible Value at Risk movements. Risk estimation on emerging markets can be focused on methodology using extreme value theory that is more sophisticated as it has been proven to be the most cautious model when dealing with turbulent times and financial turmoil.

Keywords: extreme value theory, Value at Risk, fat tails, GARCH, RiskMetrics, peak over threshold, generalized Pareto distribution

JEL classification: C13, C22, G10

Paper type: Research article

Received: 10 $10^{\text {th }}$ May, 2014

Accepted: $31^{\text {st }}$ October, 2014

Citation: Cerović, J., Lipovina-Božović, M., Vujošević, S. (2015). "A Comparative Analysis of Value at Risk Measurement on Emerging Stock Markets: Case of Montenegro", Business Systems Research, Vol. 6, No.1, pp. 36-55.

DOI: 10.1515/bsrj-2015-0003 


\section{Introduction}

The risk from extreme events is present in all fields of risk management, especially in financial markets. Methodology used for the assessment of financial markets participants' rate of exposition to risk, gives the estimation of value at risk (Cerović, 2014). Value at risk (Value-at-risk, or abbreviated VaR) is the maximum loss of financial position over a given time period at a given confidence interval (Jorion, 2007). It includes all types of financial risk and the application in the analysis of market risk is to be presented in this manuscript.

Recent approaches to quantification of market risk using econometric evaluation, RiskMetrics methodology, quantile estimation and estimation based on extreme value theory are presented in many papers. Econometric evaluation is derived from GARCH model, while RiskMetrics methodology uses integrated GARCH (IGARCH) model. Da Silva, Beatriz, and de Melo Mendes (2003), Gencay and Selcuk (2004), Bao, Lee, and Saltoglu (2006), Žiković (2007) and Bučevska (2013), among others, used GARCH models in market risk evaluation. Quantile estimation assumes that the return distribution in future is the same as in the sampling period, and $V a R$ is calculated as a quantile of its cumulative distribution (Tsay, 2010). Extreme value theory is a well-known technique used in numerous fields of applied sciences (Onour, 2010; Gilli and Kelezi, 2006; McNeil, et al. 2005; McNeil and Frey, 2000; Longin, 1996; etc). When dealing with extreme value theory in practice the peak over threshold method is often used and it models a distribution of excess over a given threshold.

The purpose of this paper is to compare performance of econometric models, quantile estimation and extreme value theory in evaluating Value-at-Risk in Montenegrin stock exchange over long period that includes years of financial crisis. Results will be interesting given the recession period is included, and are relevant on micro and macroeconomic level. In particular, the manuscript investigates whether extreme value theory can outperform econometric calculation of $\mathrm{VaR}$ in Montenegrin emerging stock market. Insofar, Montenegrin stock market in VaR modeling has been discussed in empirical literature recently. Karadžić and Cerović (2014) investigated whether asymmetric GJR GARCH model is appropriate in evaluation of VaR in emerging stock markets of the Western Balkans, so this analysis included Montenegro in comparing relative performance of only econometric VaR modeling of four countries of the Western Balkans (Croatia, Serbia, Bosnia and Herzegovina and Montenegro) with Slovenian case. The contribution of this paper is to extend the limited empirical research on VaR estimation and forecasting in emerging financial markets by comparing performance of econometric models, quantile estimation and extreme value theory on Montenegrin stock market for the first time.

The paper is organized as follows. A brief literature review is presented in next section. The third section reviews the methodology used in VaR calculation. Data and descriptive statistics are given in fourth section. The fifth section presents empirical results, and discussion with conclusion is presented in the sixth section.

\section{Literature review}

There is a general opinion in literature data that there is no universal model giving the best estimation and forecast of VaR. Numerous papers observing the application of different approaches in developed financial markets confirm this, e.g. - Manganelli and Engle (2001), Christoffersen, et al. (2001), Angelidis, et al. (2004), Wong, et al. (2002), Alexander and Leigh (1997), Harmantzis, et al. (2006), Embrechts, et al. (1998), McNeil, et al. (2005), Guermat and Harris (2002). 
On the other hand, there are very few papers observing the comparison of VaR models in developing financial markets. Gençay and Selçuk (2004) analyzed parameter models and quantile estimation of VaR of stock exchange indices in developing Central and Eastern European countries. Their results show that generalized Pareto distribution and extreme value theory are basic tools in risk management in developing countries. Žiković (2007) observed different approaches to VaR measuring on the example of new members and candidate countries for EU membership. The conclusion of this research is that application of VaR models is not successful enough in financial markets of these countries because the returns show the existence of heavy tails, asymmetry and heteroscedasticity. Further researches followed in 2009, where Žiković and Aktan (2009) analized VaR models of the returns of Turkish and Croatian stock-exchange indices with the onset of global financial crisis. It was concluded in this paper that extreme value theory and hybrid historical simulation are the best, while other models underestimate the level of risk. Anđelić, Djaković and Radišić (2010) observed Slovenian, Croatian, Serbian and Hungarian markets and concluded that under stable market conditions, the analyzed models give good forecasts of VaR estimations with $5 \%$ level of significance, while, under the conditions of market volatility, analyzed models give good estimations of VaR parameters with 1\% level of significance. Anđelić, Milošev and Djaković (2010) investigated the performance of extreme value theory with the daily stock index returns of four different emerging markets (Serbian, Croatian, Slovenian and Hungarian stock indices), and concluded that EVT approach should include continuous monitoring, with special emphasis on the role of optimal threshold determination. Nikolić-Đorić and Đorić (2011) observed the movement of stockexchange index in Serbian financial market and concluded that GARCH models combined with extreme value theory - peaks over threshold method, decrease the mean value of VaR, as well as that given models are better than RiskMetrics method and IGARCH model. Also, Mladenović, Miletić and Miletić (2012), based on analysis of stock-exchange indices in Central and Eastern European countries (Bulgaria, Czech Republic, Hungary, Croatia, Romania and Serbia), came to conclusion that the methodology of extreme value theory is slightly better than GARCH model regarding the calculation of VaR, but general suggestion is to use both approaches for better measuring of market risk.

Insofar, Montenegrin stock market has not been discussed in empirical literature until recently, so the main contribution of this paper is to extend the limited empirical research on VaR estimation and forecasting in emerging financial markets. The capital market in Montenegro is characterized by a relatively simple structure. A strong growth in the Montenegrin stock market begins in 2005, continued in 2006, and finally in 2007 it reached a peak. After that, bubble begins to crack and what followed was a drastic fall in prices (80-85\%) in the end of 2007 and in 2008 . The general "lethargy" of the market has continued until the end of 2013. A key trend in the Montenegrin economy in the last decade is certainly a strong inflow of foreign direct investments, which has acted as a strong positive shock to economic growth, but also as a shock to many other macroeconomic variables. A positive shock inflow of foreign direct investment hit both the capital market and real estate market. The slightly positive trend from 2009 is mostly due to part of privatization of EPCG (Elektropivreda Crne Gore, a. d. Niksic). If there was not the set of these transactions (which affected the sales and prices of other securities), the state in capital market of Montenegro would hardly deviated significantly from the rest of the period 20082013. The year 2009, was actually a recession year, and this year is with a high rate of decline in economic activity. 
Table 1

Brief review of research insofar

\begin{tabular}{|c|c|c|c|c|}
\hline Author(s) & Year & Countries & Used methods & Short conclusion \\
\hline $\begin{array}{l}\text { Gençay, } \\
\text { Selçuk }\end{array}$ & 2004 & $\begin{array}{l}\text { CEE } \\
\text { countries }\end{array}$ & $\begin{array}{l}\text { Parameter models } \\
\text { and } \\
\text { simulation historical }\end{array}$ & $\begin{array}{l}\text { GPD and EVT are the best for } \\
\text { developing countries. }\end{array}$ \\
\hline Žiković & 2007 & $\begin{array}{l}10 \text { EU new } \\
\text { member } \\
\text { states and } \\
\text { candidate } \\
\text { countries } \\
\text { for EU }\end{array}$ & $\begin{array}{l}\text { ARMA-GARCH } \\
\text { models and hybrid } \\
\text { historical simulation }\end{array}$ & $\begin{array}{l}\text { The application of VaR models } \\
\text { is not successful enough in } \\
\text { financial markets of these } \\
\text { countries because the returns } \\
\text { show the existence of heavy } \\
\text { tails, asymmetry and } \\
\text { heteroscedasticity. }\end{array}$ \\
\hline $\begin{array}{l}\text { Žiković, } \\
\text { Aktan }\end{array}$ & 2009 & $\begin{array}{l}\text { Croatia } \\
\text { and } \\
\text { Turkey }\end{array}$ & $\begin{array}{l}\text { Conditional and } \\
\text { unconditional EVT; } \\
\text { hybrid historical } \\
\text { simulation, GARCH } \\
\text { models }\end{array}$ & $\begin{array}{l}\text { EVT and hybrid historical } \\
\text { simulation are the best; other } \\
\text { models underestimate the level } \\
\text { of risk. }\end{array}$ \\
\hline $\begin{array}{l}\text { Anđelić, } \\
\text { Djaković, } \\
\text { Radišić }\end{array}$ & 2010 & $\begin{array}{l}\text { Slovenia } \\
\text { Croatia, } \\
\text { Serbia } \\
\text { and } \\
\text { Hungaria }\end{array}$ & $\begin{array}{l}\text { Historical simulation } \\
\text { and delta normal } \\
\text { VaR }\end{array}$ & $\begin{array}{l}\text { Under stable market conditions, } \\
\text { the analyzed models give } \\
\text { good forecasts of VaR } \\
\text { estimations with } 5 \% \text { level of } \\
\text { significance, while, under the } \\
\text { conditions of market volatility, } \\
\text { good estimations of VaR } \\
\text { parameters are obtained with } \\
1 \% \text { level of significance. }\end{array}$ \\
\hline $\begin{array}{l}\text { Anđelić, } \\
\text { Milošev, } \\
\text { Djaković }\end{array}$ & 2010 & $\begin{array}{l}\text { Slovenia } \\
\text { Croatia, } \\
\text { Serbia } \\
\text { and } \\
\text { Hungaria }\end{array}$ & EVT & $\begin{array}{l}\text { EVT approach should include } \\
\text { continuous monitoring, with } \\
\text { special emphasis on the role of } \\
\text { optimal threshold } \\
\text { determination }\end{array}$ \\
\hline $\begin{array}{l}\text { Nikolić- } \\
\text { Đorić, Đorić }\end{array}$ & 2011 & Serbia & $\begin{array}{l}\text { Garch models } \\
\text { combined with EVT } \\
\text { (POT method), } \\
\text { RiskMetrics } \\
\text { (IGARCH) }\end{array}$ & $\begin{array}{l}\text { GARCH models combined with } \\
\text { extreme value theory - peaks } \\
\text { over threshold method, } \\
\text { decrease the mean value of } \\
\text { VaR, as well as that given } \\
\text { models are better than } \\
\text { RiskMetrics method and } \\
\text { IGARCH model }\end{array}$ \\
\hline $\begin{array}{l}\text { Mladenović, } \\
\text { Miletić, } \\
\text { Miletić }\end{array}$ & 2012 & $\begin{array}{l}\text { Bulgaria, } \\
\text { Czech } \\
\text { Republic, } \\
\text { Hungary, } \\
\text { Croatia, } \\
\text { Romania } \\
\text { and } \\
\text { Serbia }\end{array}$ & $\begin{array}{l}\text { Garch models and } \\
\text { EVT }\end{array}$ & $\begin{array}{l}\text { The methodology of extreme } \\
\text { value theory is slightly better } \\
\text { than GARCH model regarding } \\
\text { the calculation of VaR, but } \\
\text { general suggestion is to use } \\
\text { both approaches }\end{array}$ \\
\hline
\end{tabular}

Source: Author's calculation

A sample period (from $5^{\text {th }}$ January 2004 to $21^{\text {st }}$ February 2014) covers the period of the financial crisis, and it is known that, in such circumstances, it is important for investors to locate risk and measure it in the best way possible. For this reason, the research results may have important implications for investors and risk managers who 
operate in the turbulent markets of countries that are still developing. The reason for that is a fact that these markets are much less liquid and have a significantly smaller market capitalization. Because of these conditions, there is a need for modelling tail distribution in these markets.

Furthermore, these results refer to Montenegrin stock market which is a small emerging economy. That is, however, the main limitation of this study and the results obtained in the analysis cannot be generalized on emerging financial markets.

\section{Methodology}

We are going to observe a portfolio of some risky assets and determine portfolio value as $V_{t}$ at a moment in time $t$. Let us assume that we want to determine the level of risk over the period $[t, t+h]$. We mark the random variable of portfolio loss as $L_{t+h}=-\left(V_{t+h}-V_{t}\right)=\Delta V(h)$. Cummulative function of loss distribution is marked as $F_{L}$ where $F_{L}(x)=P(L \leq x)$. In this case, VaR at significance level a $(\alpha \in(0,1)$ - most often $a=0.01$ or $a=0.05$, i.e. $1 \%$ and $5 \%$ ) is actually an a-quantile of distribution function $F_{L}$ and represents the smallest real number satisfying the inequation $F_{L}(x) \geq \alpha$, i.e.:

$$
\operatorname{VaR}_{\alpha}=\inf \left(x \mid F_{L}(x) \geq \alpha\right) .
$$

The type of value at risk estimation can be: 1. Econometric evaluation (GARCH models), 2. Quantile estimation (historical simulation), and 3. Estimation based on extreme value theory.

\section{GARCH model}

Generalized autoregressive conditional heteroscedasticity (GARCH) model, introduced by Bollersev (1986) and Taylor (1986), represents the generalization of autoregressive conditional heteroscedasticity model - ARCH, developed by Engle in 1982. Log returns, usually expressed in percents, are marked as $r_{\text {t. }}$ Innovation at moment $t$ is $a_{t}=r_{t}-\mu_{t}$. Then, the model can be presented as follows (Tsay, 2010):

$$
\begin{aligned}
& r_{t}=\varphi_{0}+\sum_{i=1}^{p} \varphi_{i} r_{t-i}+a_{t}-\sum_{j=1}^{a} \theta_{j} a_{t-j} \\
& a_{t}=\sigma_{t} \varepsilon_{t} \\
& \sigma_{t}^{2}=\alpha_{0}+\sum_{i=1}^{u} \alpha_{i} a_{t-i}^{2}+\sum_{j=1}^{\nu} \beta_{j} \sigma_{t-j}^{2} .
\end{aligned}
$$

Parameters of equation (2) representing autoregressive moving-average model (ARMA) of orders $p$ and $q$, ARMA $(p, q)$, are marked as $\varphi_{0}, \varphi_{1}, \ldots, \varphi_{p}, \theta_{1}, \ldots, \theta_{q}$. The random member of the model, $a_{t}$, is the function of $\varepsilon_{t}$ - series of independent and identically distributed random variables having a normal or t-distribution with zero mean and variance equal to 1. By the second equation in the model - (3), conditional variance of returns $r_{t}$ is modeled, $\sigma_{t}^{2}=E\left(\left(r_{t}-E\left(r_{t}\right)\right)^{2} \mid \Omega_{t-1}\right)$, where $\Omega_{t-1}$ is available data set with moment $t-1$ inclusive. In other words, conditional variance (volatility) is expected squared deviation of observations from the mean given the available data set.

Parameters $\alpha_{0}, \alpha_{1}, \ldots, \alpha_{v}, \beta_{1}, \ldots, \beta_{v}$ of conditional variance equation satisfy the conditions $\alpha_{0}>0, \alpha_{1}, \ldots, \alpha_{u} \geq 0, \beta_{1}, \ldots, \beta_{v} \geq 0, \sum_{i=1}^{\max (u, v)}\left(\alpha_{i}+\beta_{i}\right)<1$. 
If the series $\varepsilon_{f}$ is a random variable with standardized normal distribution, i.e. $\varepsilon_{t}: N(0,1)$, then conditional distribution of random variable $r_{h+1}$ for available data with the moment $h$ inclusive, also has a normal distribution with mean $\hat{r}_{h}(1)$ and variance $\hat{\sigma}_{h}^{2}(1)$. Then, 5\%-quantile of conditional distribution, representing the estimation of VaR at $95 \%$ confidence level and for forecast horizon 1 step ahead, is computed as:

$$
\hat{r}_{h}(1)+1,65 \hat{\sigma}_{h}(1) \text {. }
$$

If random variable $\varepsilon_{t}$ has Student's $t$ distribution, with $u$ degrees of freedom, then the $5 \%$-quantile of conditional distribution is computed as follows:

$$
\hat{r}_{h}(1)+\frac{t_{v}(1-p)}{\sqrt{\frac{v}{v-2}}} \hat{\sigma}_{h}(1),
$$

where $t_{v}(1-p)$ is the corresponding critical value of (1-p) quantile from $t$ distribution with $u$ degrees of freedom.

$\operatorname{GARCH}(1,1)$ model has the following form:

$$
\begin{aligned}
& r_{t}=\varphi_{0}+\sum_{i=1}^{p} \varphi_{i} r_{t-i}+a_{t}-\sum_{j=1}^{a} \theta_{j} a_{t-j} \\
& a_{t}=\sigma_{t} \varepsilon_{t}, \quad \varepsilon_{t}: N(0,1) \\
& \sigma_{t}^{2}=\alpha_{0}+\alpha_{1} a_{t-1}^{2}+\beta_{1} \sigma_{t-1}^{2} .
\end{aligned}
$$

If the model GARCH $(1,1)$ satisfies the parameters sum $\alpha_{1}+\beta_{1}=1$, then the model describes the process of unlimited growth of conditional variability. Such a model is known as integrated GARCH model - IGARCH(1,1). It is in the basis of VaR estimation, representing the standard approach to risk measuring - RiskMetrics.

This methodology was developed by company J. P. Morgan (Longerstaey et al., 1995), and it implies that conditional distribution of the series of log daily returns is $r_{t} \mid \Omega_{t-1}: N\left(\mu_{t}, \sigma_{t}^{2}\right)$, where $\mu_{t}$ is conditional mean, and $\sigma_{t}^{2}$ is conditional variance of series $r_{\text {t. }}$ The following relations are valid for them:

$$
\mu_{+}=0, \quad \sigma_{+}^{2}=\alpha \sigma_{t-1}^{2}+(1-\alpha) r_{t-1}^{2}, \quad 0<\alpha<1
$$

Volatility forecast for one period ahead in time shows that $\sigma_{t+1}^{2}=\alpha \sigma_{t}^{2}+(1-\alpha) r_{t}^{2}$. The previous relation indicates that $\operatorname{Var}\left(r_{t+i} \mid \Omega_{t}\right)=\sigma_{t+1}^{2}$ for $i \geq 1$, and therefore, $\sigma_{t}^{2}[k]=k \sigma_{t+1}^{2}$. If the significance level is $5 \%$, portfolio risk according to RiskMetrics methodology is computed using formula $1.65 \sigma_{t+1}$, i.e. daily VaR value of the portfolio is

$$
V a R=\text { Value of financial position } \times 1.65 \sigma_{t+1}
$$

\section{Quantile estimation (Historical simulation)}

Historical simulation begins from the assumption that return distribution in forecast period is the same as in the sampling period. Thus, the given return values of the sample are arranged according to size into a growing series in the form $r_{(1)} \leq r_{(2)} \leq \ldots \leq r_{(n)}$ with the first minimal and last maximal value. 
Let us assume that returns are independent and identically distributed random variables with constant distribution whose probability density function is $f(x)$, and corresponding function of cumulative distribution $F(x)$. Let $x_{p}$ be $p$-quantile of the function $F(x)$. If $f\left(x_{p}\right) \neq 0$, then the statistic $r_{(l)}$, where $I=n p, 0<p<1$, has approximately normal distribution with mean value $x_{p}$ and variance $p(1-p) / n\left[f\left(x_{p}\right)\right]^{2}$ , i.e.

$$
r_{(l)}: N\left(x_{p}, \frac{p(1-p)}{n f^{2}\left(x_{p}\right)}\right), \quad I=n p .
$$

\section{Extreme Value Theory - Peaks over Threshold method (POT)}

The extreme value theory is a very good methodological frame for the research of the behavior of distribution tail. If we consider the problem of sample maximum, we come to the main mathematical problem which is in the basis of the extreme value theory.

Let $x_{1}, X_{2}, \ldots$ be the series of independent, non-degenerate random variables having an even distribution, with the common distribution function $F$. Let us observe the maximum values of variables $\left(M_{1}=X_{1}\right)$

$$
M_{n}=\max \left(X_{1}, \ldots, X_{n}\right) \text {, }
$$

where $n \geq 2$.

For the joint limiting distribution function of maxima $M_{n}$, based on the character of their independence, it is:

$$
P\left(M_{n} \leq x\right)=P\left(X_{1} \leq x, \ldots, X_{n} \leq x\right)=\prod_{i=1}^{n} P\left(X_{i} \leq x\right)=\prod_{i=1}^{n} F(x)=F^{n}(x) .
$$

We will mark the right end of distribution $F$ with

$$
x_{F}=\sup (x \in R: F(x)<1) \text {. }
$$

Then, for every $x<x_{F}$,

$$
P\left(M_{n} \leq x\right)=F^{n}(x) \rightarrow 0, \quad n \rightarrow \infty,
$$

and, if $x_{F}<\infty$, for $x \geq x_{F}$

$$
P\left(M_{n} \leq x\right)=F^{n}(x)=1 .
$$

Therefore, distribution function, as $n \rightarrow \infty$, becomes degenerate. In order to obtain non-degenerate marginal distribution, it is necessary to carry out normalization (De Haan et al., 2006).

The problem comes to the determination of real constants $a_{n}>0$ and $b_{n}$, so the variable $\frac{M_{n}-b_{n}}{a_{n}}$ has non-degenerate marginal distribution, as $n \rightarrow \infty$, i.e. $\lim _{n \rightarrow \infty} F^{n}\left(a_{n} x+b_{n}\right)=G(x)$. G represents the non-degenerate distribution function and such distributions are called extreme value distributions.

Let the real constants be $a_{n}$ i $b_{n}\left(a_{n}>0\right)$, so for every $n$ applies

$\lim _{n \rightarrow \infty} P\left\{\left(M_{n}-b_{n}\right) / a_{n} \leq x\right\}=\lim _{n \rightarrow \infty} F^{n}\left(a_{n} x+b_{n}\right)=G(x),(16)$ 
for non-degenerate distribution function $G(x)$. If this condition applies, it is said that $F$ is in the domain of attraction of maxima from $G$, i.e. $F \in D(G)$.

Extreme value distribution includes three parameters - $\gamma$-shape parameter, $\beta_{n}$ location parameter, and $\alpha_{n}>0$ is scale parameter. They can be assessed in two ways: using parametric or non-parametric methods. Traditional approach - block maxima method largely dissipates data because only maximum values from great blocks are used. This is reported as the biggest disadvantage of this model, so in practice it is increasingly being replaced with the method based on peaks over threshold, where all data representing extremes are used, in the context of exceeding some high level. The given method is to be exposed as follows.

If we mark a certain threshold as $u$, and observe the series of daily log returns $r_{f}$, then if $i^{\text {th }}$ excess happens on the $i^{\text {th }}$ day, this model is focused on the data $\left(t_{i}, r_{t_{i}}-u\right)$. The basic theory of this new approach observes conditional distribution from $r=x+u$ which is for $r \leq x+u$ given that threshold is exceeded, $r>u$ :

$$
P(r \leq x+u \mid r>U)=\frac{P(U \leq r \leq x+U)}{P(r>U)}=\frac{P(r \leq x+U)-P(r \leq u)}{1-P(r \leq U)} \text {. }
$$

The main distribution used for the modeling of excess over the threshold is generalized Pareto distribution, defined in the following way (Tsay, 2010):

$$
G_{\gamma, \psi(u)}(x)= \begin{cases}1-\left(1+\frac{\gamma x}{\psi(u)}\right)^{-1 / \gamma}, & \gamma \neq 0, \\ 1-\exp \left(-\frac{x}{\psi(u)}\right), & \gamma=0,\end{cases}
$$

where $\psi(u)>0$, and $x \geq 0$ for $\gamma \geq 0$, and $0 \leq x \leq-\psi(u) / \gamma$ when $\gamma<0$. Therefore, we conclude that conditional distribution from $r$, if $r>u$, approximates well with generalized Pareto distribution with parameters $\gamma$ and $\psi(u)=\alpha+\gamma(u-\beta)$. Parameter $\psi(u)$ is called scale parameter, and $\gamma$ is shape parameter.

Generalized Pareto distribution has a very significant feature. If the excess distribution from $r$ with the given threshold $v_{0}$ is generalized Pareto distribution with shape parameter $\gamma$ and scale parameter $\psi\left(u_{0}\right)$, then for arbitrary threshold $u>U_{0}$, the given excess distribution for threshold $u$ is also generalized Pareto distribution with shape parameter $\gamma$ and scale parameter $\psi(U)=\psi\left(U_{0}\right)+\gamma\left(U-U_{0}\right)$.

When the parameter $\gamma=0$, then generalized Pareto distribution is exponential distribution. Therefore, it is suggested to carry out a graphic examination of the tail behavior using $Q Q$ plot. If $\gamma=0$, then the graph of the excess is linear.

Peaks over threshold model has a problem regarding the choice of an adequate threshold. This is how the given problem is usually solved in practice.

For the given high threshold $u_{0}$, let the excess $r-u_{0}$ follow generalized Pareto distribution with parameters $\gamma$ and $\psi\left(U_{0}\right)$, where $0<\gamma<1$. Then, the mean excess over the threshold $u_{0}$ :

$$
E\left(r-U_{0} \mid r>U_{0}\right)=\frac{\psi\left(U_{0}\right)}{1-\gamma}
$$

The mean excess function $e(u)$ is defined, for every $u>u_{0}$, as: 


$$
e(u)=E(r-u \mid r>u)=\frac{\psi\left(u_{0}\right)+\gamma\left(u-u_{0}\right)}{1-\gamma}
$$

Therefore, for the given value $\gamma$, the mean excess function is the linear function of excess $u-u_{0}$. Hence, for the determination of the given threshold $u_{0}$, a simple graphic model is used, forming the empirical mean excess function as

$$
e_{T}(U)=\frac{1}{N_{u}} \sum_{i=1}^{N_{u}}\left(r_{t_{i}}-U\right)
$$

where $N_{u}$ is the number of returns exceeding the threshold $u$, and $r_{t_{i}}$ are the values of given returns. Threshold $u$ is chosen so the empirical mean excess function is approximately linear for $r>U$.

For the given probability $p$ in the upper tail, (1-p)-quantile of log return $r_{f}$ is

$$
\operatorname{VaR}=\left\{\begin{array}{cc}
\beta-\frac{\alpha}{\gamma}\left\{1-[-D \ln (1-\mathrm{p})]^{-\gamma}\right\} & \gamma \neq 0, \\
\beta-\alpha \ln [-D \ln (1-\mathrm{p})] & \gamma=0 .
\end{array}\right.
$$

To illustrate these methods, we will use data that are explained in the next section.

\section{Data and descriptive statistics}

We examined daily log returns of Montenegrin stock index MONEX20 that is the adequate indicator of the state of Montenegrin stock market. Stock market index MONEX20 consists of 20 the most liquid stocks from Montenegrin stock market, so this is why it best reflects the price movements on Montenegrin market (All mentioned references in this paper examined stock market indices of aforementioned countries). MONEX20 is weighted index - each issuer's share is determined by its capitalization. The market capitalization includes ordinary shares that are in free float. Shares of twenty the best ranked companies by liquidity ratio constitute MONEX20. MONEX20 index is calculated according to the following formula

$$
\text { MONEX20 }=\frac{\sum_{i=1}^{n} p_{i, t} \cdot q_{i, R}}{\sum_{i=1}^{n} p_{i, 0} \cdot q_{i, R}} \cdot 1000 \cdot C_{T} \text {, }
$$

where $p_{i, t}$ is price of $i^{\text {th }}$ stock on day $t, p_{i, 0}$ is base price of $i^{\text {th }}$ stock on the date of formation of the index, $a_{i, R}$ is number of stocks in free float, and $C_{T}$ is correction factor for ensuring continuity of the index in the time before calculation of the index at new composition.

Time series of observed log returns of stock index MONEX20 on daily basis consists of 2508 data in total (from $5^{\text {th }}$ January 2004 to $21^{\text {st }}$ February 2014), and it is presented in Figure 1. Log daily returns (or continuously compounded returns) represent the difference between logarithmic levels of prices in two successive days. It can also be expressed in percents, when these differences are multiplied by 100. The data are taken from the website of Montenegro Stock Exchange (http://www.montenegroberza.com). Empirical results are obtained by using program package R.

Expressed volatility of Montenegrin stock index MONEX20 which includes the 20 most liquid stocks from Montenegrin capital market can be seen on Figure 2. It is also 
evident that this series is stationary. Its empirical distribution deviates from normal distribution, as $Q-Q$ plot (Figure 3) shows. Namely, the quantiles of an empirical distribution are plotted against the quantiles of a normal distribution. From the Figure 3 it is clear that $Q Q$ plot is not linear and that empirical distribution differs from the hypothesized normal distribution. So, fat-tail nature of observed logarithmic return series is expressed, as well as skewness, kurtosis and Jarque-Bera test-statistics (JB) show. These descriptive statistics are given in Table 2 with corresponding $p$-values in parenthesis.

Table 2

Basic Descriptive Statistics of Daily Logarithmic Return for MONEX20

\begin{tabular}{|l|l|l|l|l|l|}
\hline Variance & Skewness & Kurtosis & JB & $\begin{array}{l}\text { Box-Ljung } \\
(\mathbf{m}=10)\end{array}$ & $\begin{array}{l}\text { Box-Ljung } \\
\left(a_{t}^{2}\right)\end{array}$ \\
\hline \hline 2.869291 & 0.686 & 6.537 & $\begin{array}{l}4672.701 \\
(<2.2 \mathrm{e}-16)\end{array}$ & $\begin{array}{l}219.636 \\
(<2.2 \mathrm{e}-16)\end{array}$ & $\begin{array}{l}1003.793 \\
(<2.2 \mathrm{e}-16)\end{array}$ \\
\hline
\end{tabular}

Note: Standard errors are given in parenthesis

Source: Author's calculation

Figure 1

Time Series of MONEX20 Stock Index from January 2004 to February 2014

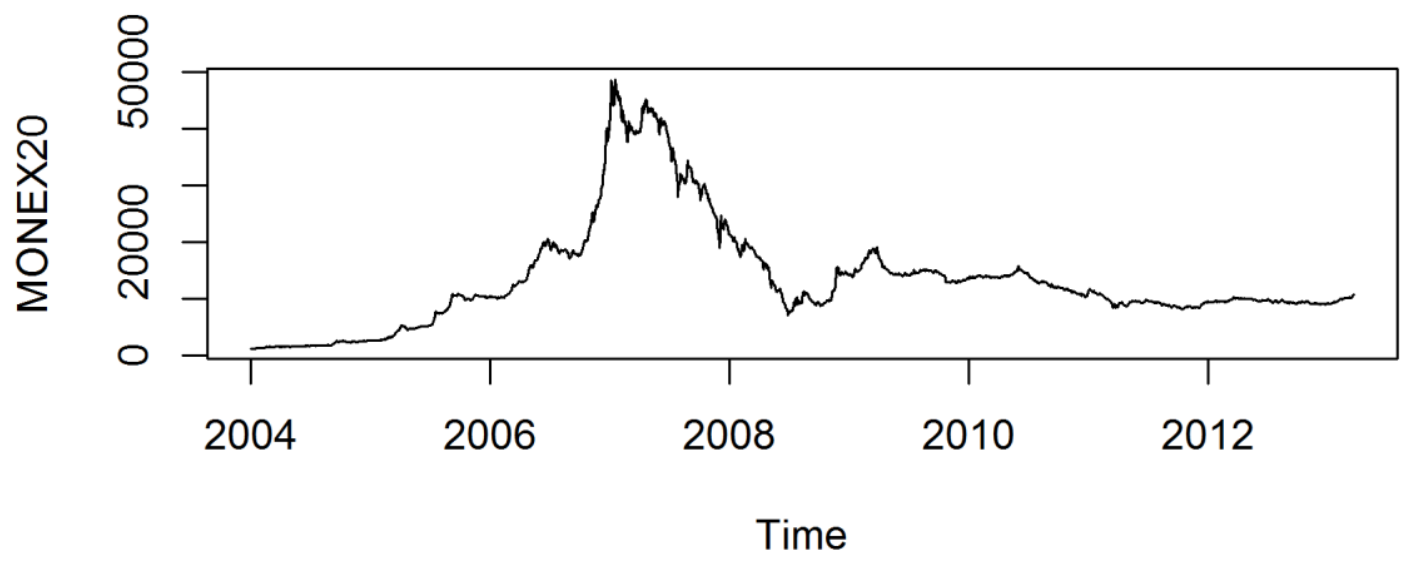

Source: Montenegro stock exchange and Author's calculation

The skewness shows that the series is not sharply asymmetric, but there is a particular positive asymmetry. Normality deviation is mostly due to high kurtosis, which means "fat tails" existence - tails are heavier than normal distribution tails.

Jarque-Bera (JB) normality test shows that the hypothesis of normality of returns can be abandoned even when the level of significance is $1 \%$. JB test-statistic has an asymptotic $\chi^{2}$ distribution with two degrees of freedom.

Box-Ljung test-statistic (Box-Ljung) is used for the determination of autocorrelation of order $m$ between squared data and has asymptotic $\chi^{2}$ distribution with $m$ degrees of freedom. Null hypothesis in this test implies that the first $m$ autocorrelation coefficients of squared data are zero and it is abandoned here. Valve $m$ is chosen in several ways and in practice the best form is $m \approx \ln (T)$, where $T$ is the number of data of the observed variable (Tsay, 2010). In our case, this value is 10. 
Figure 2

Daily Return of Monex20 Stock Index

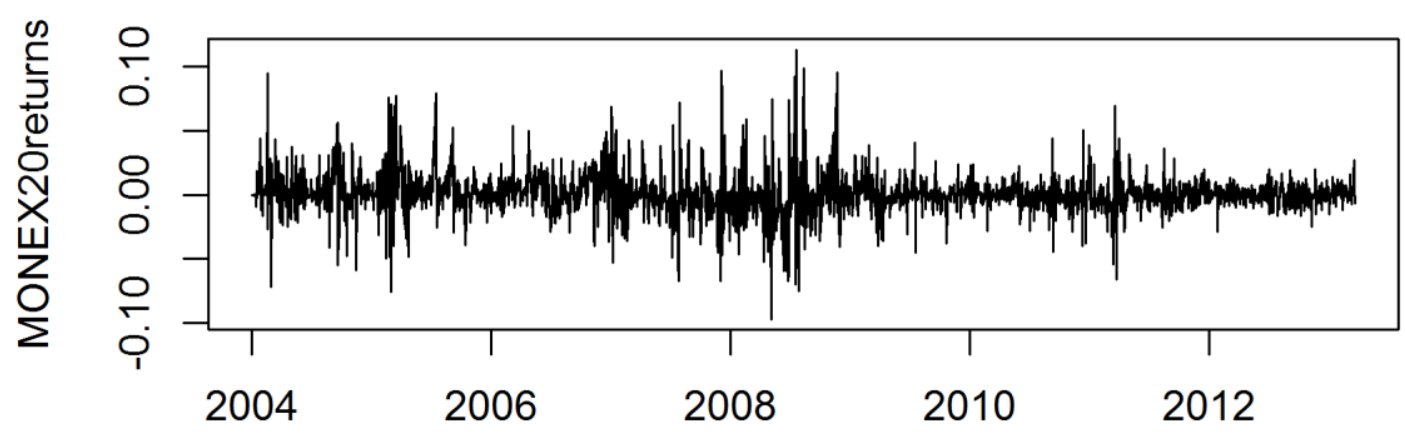

Time

Source: Montenegro stock exchange and Author's calculation

Figure 3

Q-Q Plot of Daily Return of Monex20 Relative to Normal Distribution

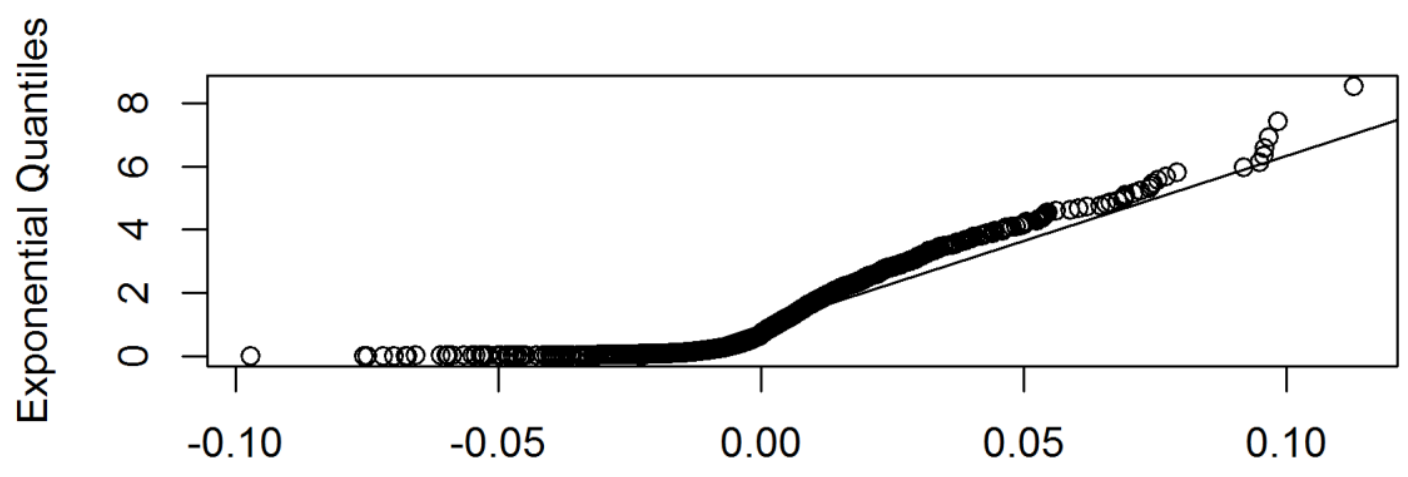

Ordered Data

Source: Author's calculation

To determine the existence of time-changing variability, the same Box-Ljung teststatistic is used, but for squared residual series (Tsay 2010). Return residual is defined as the difference between return level and mean of the return, i.e. $a_{t}=r_{t}-\mu_{t}$. For the daily logarithmic return of MONEX20, first the serial correlation was determined according to Box-Ljung test-statistic for the return data, and the same statistic for squared residuals also shows high volatility.

\section{Empirical Results}

In this part of the paper the results of the empirical research particularly focused on the application of VaR methodology on the emerging market of Montenegro are presented.

By the specification analysis based on sample functions of autocorrelation (Figure $4)$, it is estimated that the best model for modeling logarithmic return series is $\operatorname{ARMA}(2,0)$. Volatility movement is well described by model $\operatorname{GARCH}(1,1)$ with Student's t-distribution.

Jointly estimated ARMA $(2,0)-G A R C H(1,1)$ model is: 


$$
\begin{aligned}
& r_{t}=0.14806 r_{t-1}+0.07338 r_{t-1}+a_{t}, \\
& \sigma_{t}^{2}=0.11691 a_{t-1}^{2}+0.88209 \sigma_{t-1}^{2} .
\end{aligned}
$$

Table 3

Tests of ARMA $(2,0)-G A R C H(1,1)$ Model: Test-statistic and p-value

\begin{tabular}{|c|c|c|}
\hline Box-Ljung Q(10) & Box-Ljung $\left(a_{t}^{2}\right)$ & LM ARCH Test \\
\hline \hline $18.079(0.003)$ & $5.741(0.33)$ & $10.448(0.402)$ \\
\hline
\end{tabular}

Note: Standard errors are given in parenthesis

Source: Author's calculation

Figure 4

Autocorrelation Functions (ACF) for MONEX20 Series

\section{ACF of Observations}

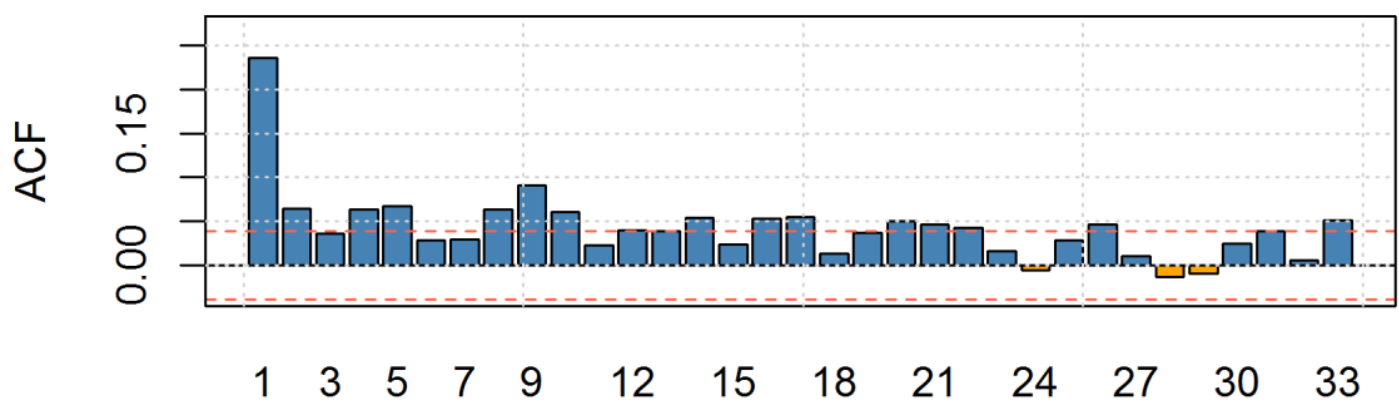

Source: Author's illustration

lag

Figure 5

Autocorrelation Function of Squared Standardized Residuals of Estimated Model $\operatorname{ARMA}(2,0)-G A R C H(1,1)$

ACF of Squared Standardized Residuals

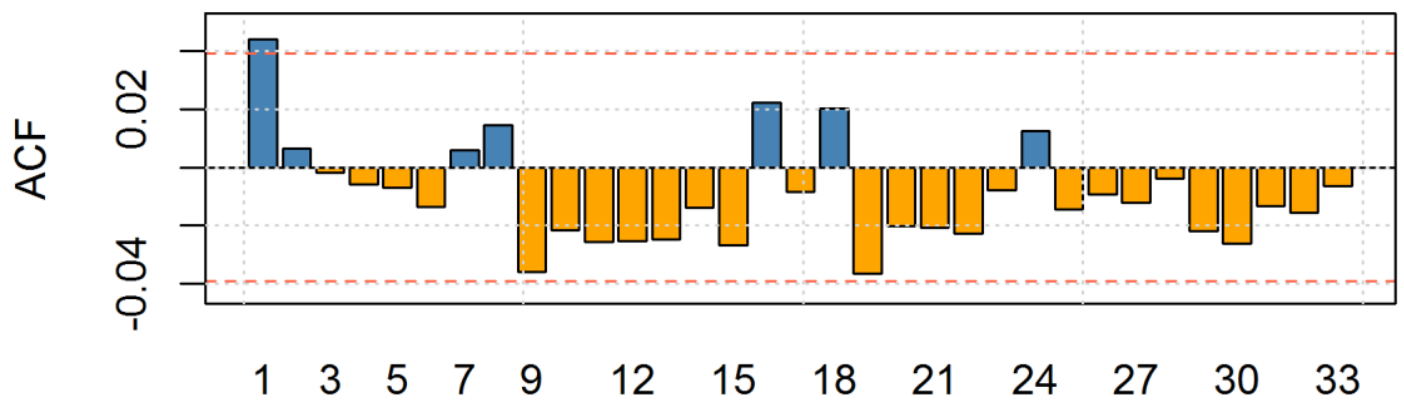

Source: Author's illustration

lag

The tests of residual normality, autocorrelation and conditional heteroscedasticity are given in Table 3. Therefore, it can be observed that the chosen model describes volatility really well. Also, the estimated GARCH model removed autocorrelation successfully, which can be seen from Box-Ljung test for squared standardized residuals. So, autocorrelation was reduced enough, which can be concluded based 
on the autocorrelation function of standardized residuals, shown in Figure 5. Figure 6 presents $Q-Q$ plot of standardized residuals, so the fit is reasonable based on this plot.

Figure 6

Q-Q plot of Standardized Residuals from Estimated Model ARMA $(2,0)-\operatorname{GARCH}(1,1)$

\section{std - QQ Plot}

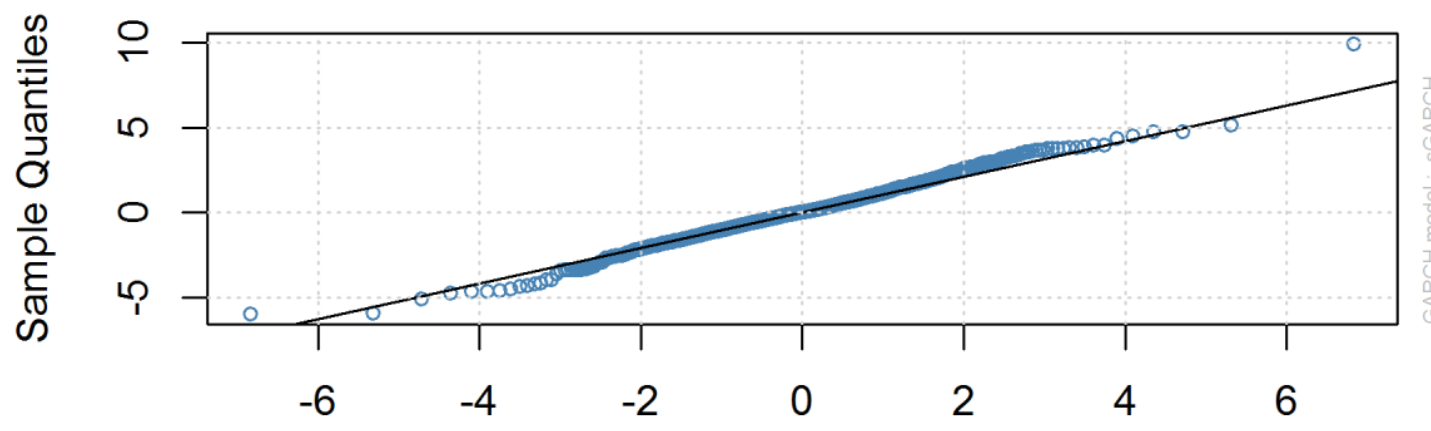

Theoretical Quantiles

Source: Author's illustration

In Table 4, forecasted levels of return and volatility (conditional standard deviations) for one day time horizon, which are used for the evaluation of VaR, are presented. The evaluation is computed for level of confidence $95 \%$ and $99 \%$.

Interpretation of the obtained result for $\mathrm{VaR}$ is as follows: if one possesses some value of stocks (for example, 1000€), described by stock market index MONEX20, then the possible loss for the owner of stocks for a one-day period, does not exceed $1.518 \%$ of the value $(15.18 €)$ with probability $95 \%$. With the $99 \%$ probability, the estimation of the maximum loss is $2.573 \%$ of the value $(25.73 €)$.

Table 4

Econometric Evaluation of VaR for a One-Day Period (MONEX20 return)

\begin{tabular}{|c|c|c|c|}
\hline Return forecast & $\begin{array}{c}\text { Forecast of } \\
\text { conditional st. dev. }\end{array}$ & VaR (95\%) & VaR (99\%) \\
\hline \hline-0.0005641 & 0.0101 & $1.518 \%$ & $2.573 \%$ \\
\hline
\end{tabular}

Source: Author's calculation

Riskmetrics method for the calculation of VaR assumes that conditional mean value is zero and that return volatility follows IGARCH(1,1) model. The adjusted model is

$$
r_{t}=a_{t}, \quad a_{t}=\sigma_{t} \varepsilon_{t}, \quad \sigma_{\dagger}^{2}=0.079913 \sigma_{t-1}^{2}+(1-0.079913) a_{t-1}^{2},
$$

where $\varepsilon_{t}$ is standard Gaussian series of white noise. Q statistic for squared standardized residuals is statistically significant and equals 19.54.

Following the adjusted model, volatility forecast for one period in advance is $\hat{\sigma}(1)=0.00976$, so $95 \%$ quantile of conditional distribution is $1.65 \times 0.00976=0.016104$, or $1.6104 \%$. VaR for $95 \%$ probability, one period in advance, for the position of, for example, $1000 €$, will be:

$\operatorname{VaR}=1000 € \times 0.016104=16.104 €$. 
According to the same principle, $99 \%$ quantile is $2.326 \times 0.00976=0.02270176$, so VaR, for the given probability is approximately $22.7 €$ (approximately $2.27 \%$ ).

Quantile assessment of VaR is obtained as empirical $99 \%$ quantile, with the value of daily logharitmic return for MONEX20. It is $4.722598 \%$, which means if we possess $1000 €$ of stocks described by stock market index MONEX20, the loss in one-day period does not exceed $47.226 €$, with $99 \%$ probability. With confidence level $95 \%$, VaR amounts to $2.381442 \%$.

The following is the evaluation of VaR based on the new approach of extreme value theory - peaks over threshold method. Negative logarithmic returns of MONEX20 stock index are observed, and selection for threshold $u$ is based on the graph of mean excess function. The graph of mean excess function has linear tendency from the threshold level 2-3\%, which can be seen from Figure 7, so we give results for 3 varying values of threshold: $2 \%, 2.5 \%$ and $3 \%$.

The set of extreme events exceeding the $2.5 \%$ threshold has 115 data. For thresholds of $2 \%$ and $3 \%$, the numbers of exceeding are 160 and 77 , respectively. Based on these data sets, the distribution of maximal negative logarithmic returns for MONEX20 is modeled. Table 5 contains the evaluate parameters $\gamma, \alpha$ and $\beta$ for the given data sets, with given variation of threshold from $2 \%$ to $3 \%$. Given parameters are used for the calculation of VaR and the adequacy of the given model can be based on plots which can be seen in Figures $8-11$.

Figure 7

Mean Excess Function Plot for Daily Negative Log Returns of MONEX20

\section{Mean excess plot}

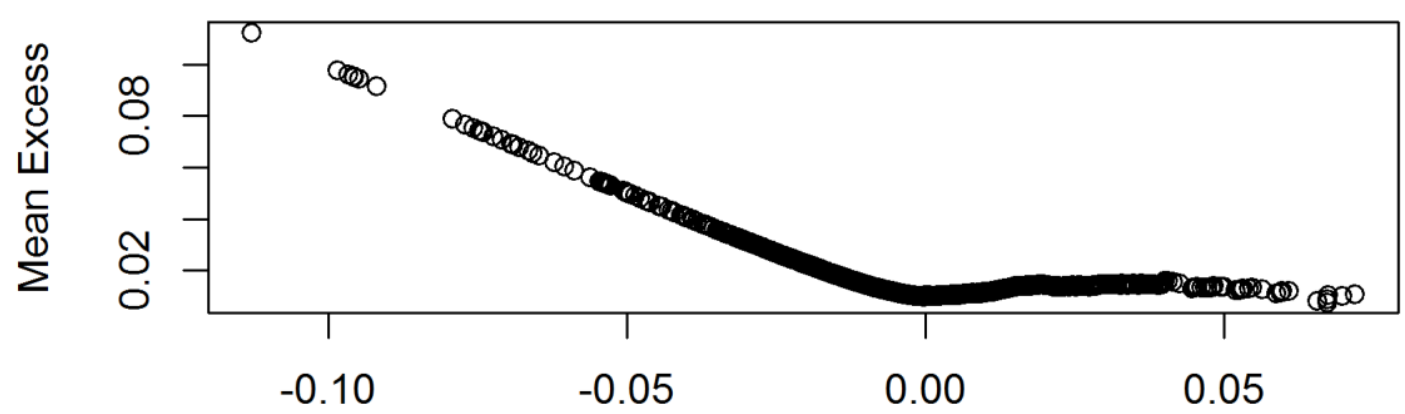

Threshold

Source: Author's illustration

Table 5

Result Estimates of Two-Dimensional Poisson Process of MONEX20 Daily Negative Log Returns

\begin{tabular}{|r|r|l|c|c|}
\hline \multicolumn{1}{|c|}{ Threshold } & $\begin{array}{c}\text { Number of } \\
\text { exceeding }\end{array}$ & $\gamma_{n}$ & $\alpha_{n}$ & $\beta_{n}$ \\
\hline $3 \%$ & 77 & $-0.103(0.08)$ & $0.023(0.008)$ & $-0.037(0.015)$ \\
\hline $2.5 \%$ & 115 & $-0.026(0.066)$ & $0.015(0.004)$ & $-0.021(0.008)$ \\
\hline $2 \%$ & 160 & $-0.051(0.059)$ & $0.017(0.004)$ & $-0.025(0.006)$ \\
\hline
\end{tabular}

Note: Standard errors are given in parenthesis

Source: Author's calculation 
Highly adjusted generalized Pareto distribution to the daily negative log returns of MONEX20 is seen in Figures 8 and 9. Figure 8 shows exceeding fit to the generalized Pareto distribution (excess distribution), and Figure 9 shows tail of underlying distribution. At Figure 10 we present scatter plot of residuals, and Figure 11 gives $Q-Q$ plot that contains empirical quantiles that form a straight line. Hence, the empirical quantiles form approximately straight line, and we have one more indicator leading to conclusion that negative log returns of index Monex20 are properly modeled by generalized Pareto distribution.

Figure 8

Plots for Generalized Pareto Distribution to Daily Negative Log Returns of MONEX20 Excess Distribution

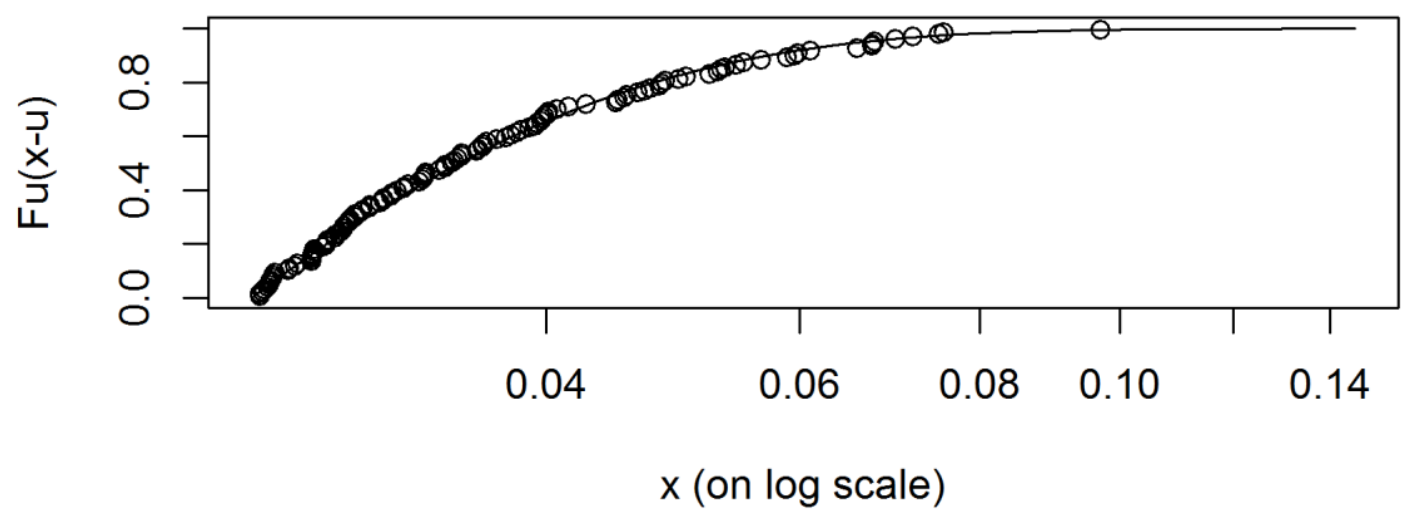

Source: Author's illustration

Figure 9

Plots for Generalized Pareto Distribution to Daily Negative Log Returns of MONEX20 Tail of Underlying Distribution

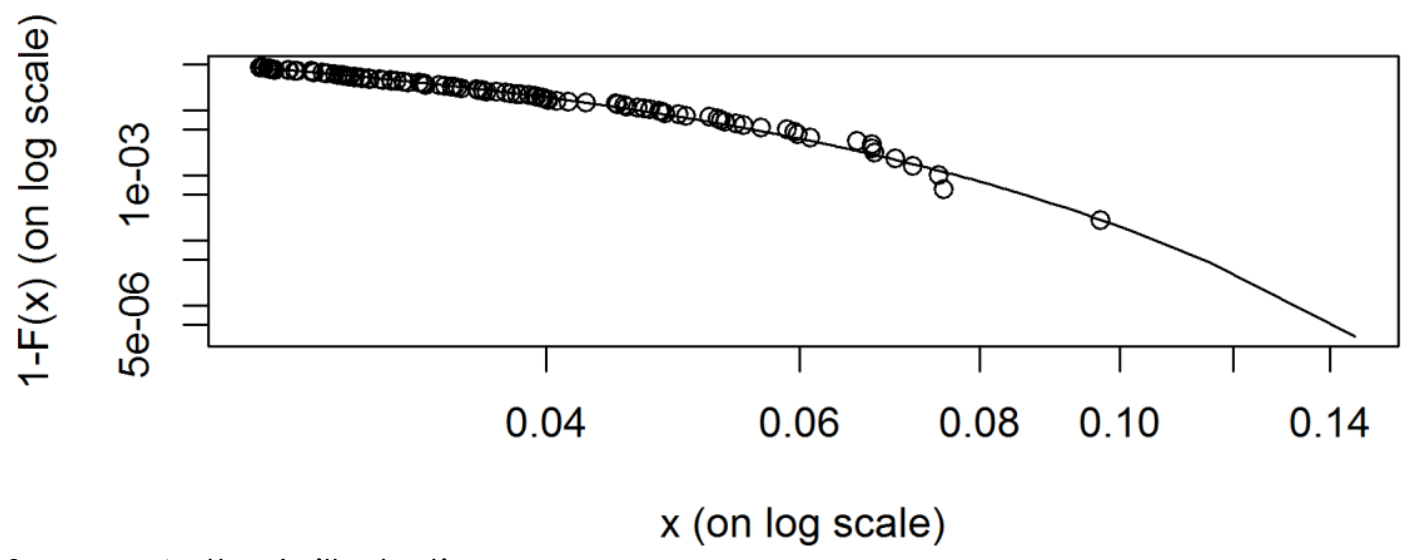

Source: Author's illustration

Peaks over thresholds method gives results for VaR summed in the Table 6. It is evident here that results of VaR differ less depending on different values of threshold excess, and with the same confidence level.

In order to compare the results, Value at risk estimates are as follows: If we possess $1000 €$ worth stocks described by stock market index MONEX20, with probability 0.05 , meaning there is $95 \%$ probability the loss would be lower or the same as VaR for the following trading day, the parameter estimated value is: 
- 15.18€ applying ARMA(2,0)-GARCH(1,1) model,

- 16.104€ when using RiskMetrics,

- 23.82€ by quantile estimation, and

- $23.8 €$ when using peak over threshold method (threshold is $2.5 \%$ ).

The corresponding $\mathrm{VaR}$ with the probability 0.01 is:

- 25.73€ applying ARMA(2,0)-GARCH(1,1) model,

- 22.7€ when using RiskMetrics,

- 47.226€ by quantile estimation, and

- $46.34 €$ when using peak over threshold method (threshold is $2.5 \%$ ).

Figure 10

Plots for Generalized Pareto Distribution to Daily Negative Log Returns of MONEX20 Scatterplot of Residuals

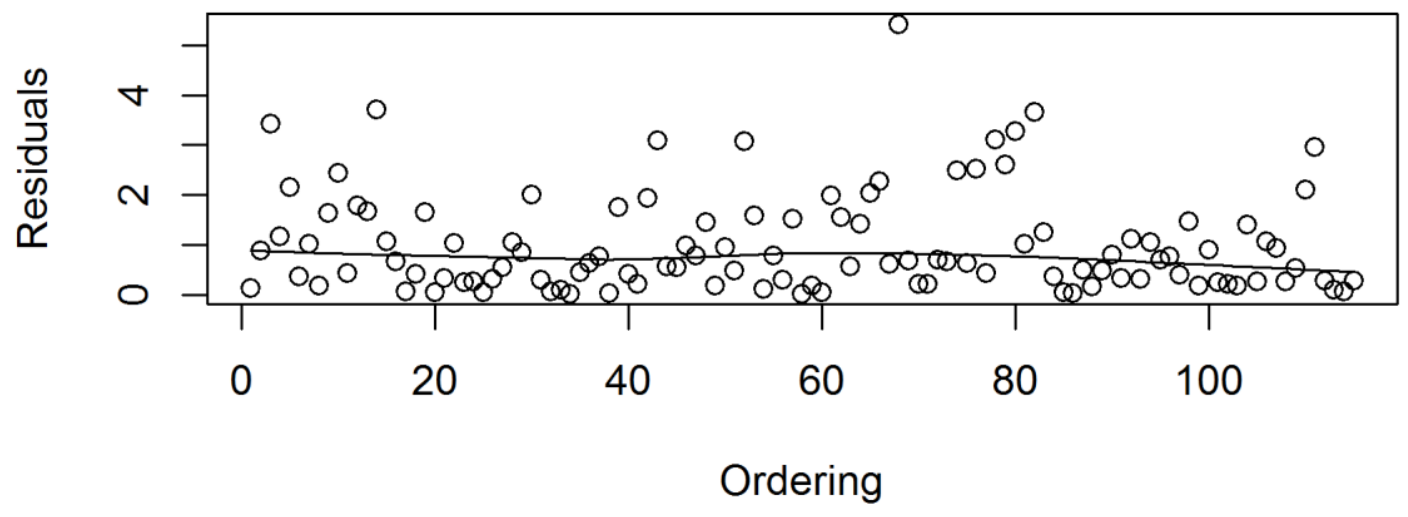

Source: Author's illustration

Figure 11

Plots for Generalized Pareto Distribution to Daily Negative Log Returns of MONEX20 Q-Q plot of Residuals

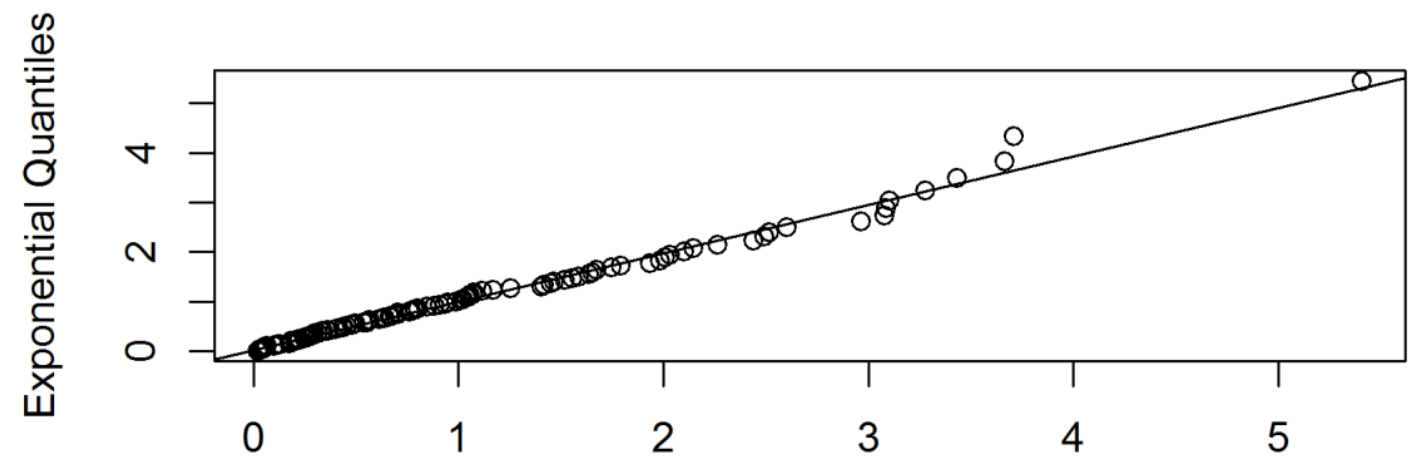

[

\section{Ordered Data}

Source: Author's illustration

Due to different treatment in the estimation of distribution tail behaviour, there are different results obtained as well. The result of econometric assessment (ARMAGARCH models and RiskMetrics), in case all assumptions for its applications are accomplished, depends on the chosen model. Therefore, it is necessary, as we have shown on the example, to have a detailed analysis of the specification of potential 
models in the first phase of the performance of Value at Risk evaluation. It can be concluded that econometric estimation is on the lower bound of possible VaR movement interval.

Table 6

Evaluation of VaR and Expected Shortfall Based on Peak over Threshold Method

\begin{tabular}{|l|r|l|}
\hline Threshold & $\boldsymbol{p}$-value & VaR \\
\hline \multirow{3}{*}{$3 \%$} & 0.05 & $2.38 \%$ \\
\cline { 2 - 3 } & 0.01 & $4.63 \%$ \\
\cline { 2 - 3 } & 0.001 & $7.70 \%$ \\
\hline \multirow{3}{*}{$2.5 \%$} & 0.05 & $2.36 \%$ \\
\cline { 2 - 3 } & 0.01 & $4.67 \%$ \\
\hline \multirow{3}{*}{$2 \%$} & 0.001 & $7.65 \%$ \\
\cline { 2 - 3 } & 0.05 & $2.20 \%$ \\
\cline { 2 - 3 } & 0.01 & $4.70 \%$ \\
\hline & 0.001 & $7.64 \%$ \\
\hline
\end{tabular}

Source: Author's calculation

Further, the choice of tail distribution probability also has an important role in the calculation of VaR. The value of the observed sample of 2508 data may be considered large enough for empirical quantiles with $99 \%$ and $95 \%$ probability for giving good parameter estimation. For both levels of significance, quantile Valve at Risk evaluation is very close to the assessment of the new approach of extreme value theory. We note that these two assessments are on the upper bound of the possible VaR parameter range.

Also, within the latter approach (Table 6), we can see that using a very low $0.1 \%$ probability, less reliable VaR evaluation are obtained. Therefore, that significance level was not used in other approaches.

\section{Discussion and Conclusion}

We discussed empirical evaluation of Value at risk in Montenegrin stock market and compare relative performance of econometric, quantile estimation and estimation based on extreme value theory. Using the daily returns of Montenegrin market index MONEX20, in the period from $5^{\text {th }}$ January 2004 to $21^{\text {st }}$ February 2014, we have measured VaR and tested performance of $\operatorname{ARMA}(2,0)-\operatorname{GARCH}(1,1)$ model with Student's t-distribution, RiskMetrics methodology $(\operatorname{IGARCH}(1,1))$, quantile estimation and estimation based on extreme value theory (peaks over threshold method).

Descriptive statistics show the presence of fat tails in observed time series, due to skewness and kurtosis, and it is concluded that its empirical distribution deviates from normal distribution. Box-Ljung test-statistic for squared residuals also shows high volatility.

Our empirical results show that extreme value theory is more adequate for estimating Value at Risk in the Montenegrin stock market comparing to econometric evaluation and quantile assessment. Namely, predictive performance of peaks over threshold method better fit residuals to generalized Pareto distribution, compared to results obtained by econometric evaluation (GARCH and IGARCH model RiskMetrics methodology) and quantile estimation. So results of analyzed methods for Montenegro are similar as for other developing countries (Gencay and Selcuk, 2004; Mladenović, Miletić and Miletić 2012).

Results of empirical analysis have multiple benefits. They show that the assessments of Value at Risk based on extreme value theory outperform 
econometric evaluations. It is obvious that econometric evaluations (ARMA $(2,0)$ GARCH $(1,1)$ and RiskMetrics) proved to be on the lower bound of possible Value at Risk movements. Therefore, it is possible to say econometric evaluations underestimate the given parameter, but the estimation should significantly change for a more volatile stock depending on the level of confidence.

Taking these results into account, a suggestion can be given to financial institutions to quantify risk using peaks over thresholds method that is the latest approach of extreme value theory, instead of historical evaluation (quantile) and econometric method. For the purpose of simplicity, risk estimation on emerging markets can be focused on methodology using extreme value theory that is more sophisticated as it has been proven to be the most cautious model when dealing with turbulent times and financial turmoil.

Furthermore, these results refer to Montenegrin stock market, that is small emerging economy and the results obtained in the analysis cannot be generalized on emerging economies and financial markets that are still developing. These markets are characterized by a greater influence of internal trade and high volatility compared to developed countries, so evaluation of VaR with standard methods that assume a normal distribution is much more difficult. Good point for future research is to use a wider sample of emerging markets (EU candidates) and compare used methodology among them in predictive performance.

Also, the observation period for measuring Value at Risk includes period of financial crisis, so that fact should be taken into account because of possible derogation of parameter results.

\section{References}

1. Alexander, C. O., Leigh, C. T. (1997), "On the covariance matrices used in Value at Risk models", Journal of Derivatives, Vol. 4, No. 3, pp. 50-62.

2. Anđelić, G., Djaković, V., Radišić, S. (2010), "Application of VaR in Emerging markets: A Case of Selected Central and Eastern European Countries", African Journal of Business Management, Vol. 4, No. 17, pp. 3666-3680.

3. Anđelić, G., Milošev, I., Djaković, V. (2010), "Extreme value theory in emerging markets", Economic Annals, Vol. LV, No. 185, pp. 63-106.

4. Angelidis, T., Benos, A., Degiannakis, S. (2004), "The use of GARCH models in VaR estimation", Statistical Methodology, Vol. 1, No. 2, pp. 105-128.

5. Bollerslev, T. (1986), "Generalized autoregressive conditional heteroskedasticity", Journal of Econometrics, Vol. 31, No. 3, pp. 307-327.

6. Bao, Y., Lee, T., Saltoglu, B. (2006), "Evaluating Predictive Performance of Value-at-Risk Models in Emerging Markets: A Reality Check", Journal of Forecasting, Vol. 25, No. 2, pp. 101-128.

7. Bučevska, V. (2013), "An Empirical Evaluation of GARCH Models in Value-at-Risk Estimation: Evidence from the Macedonian Stock Exchange", Business Systems Research, Vol. 4, No. 1, pp. 49-64.

8. Cerović, J. (2014), "Value at risk measuring and Extreme value theory: Evidence from Montenegro", Facta Universitatis, Series: Economics and Organization, Vol. 11, No. 2, pp. 175-189.

9. Christoffersen, P., Hahn, J., Inove, A. (2001), "Testing and Comparing Value-at-Risk Measures", Journal of Empirical Finance, Vol. 8, No. 3, pp. 325-342.

10.Da Silva, A., Beatriz, V., de Melo Mendes, B., (2003), "Value-at-Risk and Extreme Returns in Asian Stock markets", International Journal of Business, Vol. 8, No. 1, pp. 17-40.

11.De Haan, L., Ferreira, A. (2006). Extreme Value Theory: an Introduction. New York: Springer Science+Business Media LLC.

12.Embrechts, P., Resnick, S. I., Samorodnitsky, G. (1998), "Living on the edge", Risk, Vol. 11, No. 1, pp. 96-100. 
13.Engle, R. F. (1982), "Autoregressive Conditional Heteroscedasticity with Estimates of the Variance of United Kingdom inflation", Econometrica, Vol. 50, No. 4, pp. 987-1007.

14.Gençay, R., Selçuk, F. (2004), "Extreme value theory and value-at-risk: Relative performance in emerging markets", International Journal of Forecasting, Vol. 20, No. 2, pp. 287-303.

15. Gilli, M., Kellezi, E. (2006), "An Application of Extreme Value Theory for Measuring Financial Risk", Computational Economics, Vol. 27, No. 2, pp. 207-228.

16. Guermat, C., Harris, D. F. (2002), "Forecasting value at risk allowing for time and kurtosis of portfolio returns", International Journal of Forecasting, Vol. 18, No. 3, pp. 409-419.

17.Harmantzis, F., L. Miao, Chien, Y. (2006), "Empirical Study of Valve-at-Risk and Expected Shortfall Models with Heavy Tails", Journal of Risk Finance, Vol. 7, No. 2, pp. 117-135.

18.Jorion, P. (2007). Value at Risk: The New Benchmark for Managing Financial Risk, 3 rd ed., New York: McGraw-Hill.

19.Karadžić, V., Cerović, J. (2014), "Market Risk of the Western Balkans countries during the global financial crisis", Economic Annals-XXI, Vol. 2014, No. 11-12, pp. 19-23.

20.Longerstaey, J., More, L. (1995). Introduction to RiskMetrics. Morgan Guaranty Trust Company.

21.Longin, F. M. (1996), "The Asymptotic Distribution of Extreme Stock Market Returns", Journal of Business, Vol. 69, No. 3, pp. 383-408.

22. Manganelli, S., Engle, R. F. (2001), "Value at Risk Models in Finance", available at: http://ssrn.com/abstract=356220 (12 December 2011)

23.McNeil, A. J., Frey, R. (2000), "Estimation of tail-related risk measures for heteroscedastic financial time series: An extreme value approach", Journal of Empirical Finance, Vol. 7, No. 3-4, pp. 271-300.

24.McNeil, A.J., Frey, R., Embrechts, P., (2005). Quantitative Risk Management. Princeton: Princeton University Press.

25.Mladenović Z., Miletić, M., Miletić, S. (2012), "Value at Risk in European Emerging Economies: Empirical Assessment of Financial Crisis Period", paper presented at Scientific Conference: from Global Crisis to Economic Growth: which way to take?, 20.0922.09.2012, Faculty of Economics, Belgrade.

26.Montenegroberza AD Podgorica, available at http://www.montenegroberza.com (18.06.2013).

27.Nikolić-Đorić, E., Đorić, D. (2011), "Dynamic Value at Risk Estimation for BELEX15", Metodološki zvezki, Vol. 8, No. 1, pp. 79-98.

28.Onour, I. A. (2010), "Extreme Risk and Fat-Tails Distribution: Empirical Analysis", Journal of Money, Investment and Banking, Vol. 13, No. 13, pp. 27-34.

29.Taylor, S. (1986). Modelling Financial Time Series. Chichester: Wiley.

30.Tsay, Ruey, S. (2010). Analysis of Financial Time Series, Third Edition. Hoboken, New Jersey: John Wiley \& Sons, Inc.

31.Žiković, S., Aktan, B. (2009), "Global financial crisis and VaR performance in emerging markets: A case of EU candidate state - Turkey and Croatia", Zbornik radova Ekonomskog fakulteta u Rijeci, Vol. 27, No. 1, pp.145-170.

32.Žiković, S., (2007), "Measuring Market Risk in EU New Member States", available at: http://www.hnb.hr/dub-konf/13-konferencija/zivkovic.pdf (12 December 2011)

33.Wong, C. S., Cheng, Y. W., Wong, Y. P. (2002), "Market risk management of banks: Implications from the accuracy of VaR forecasts", Journal of Forecasting, Vol. 22, No. 1, pp. 22-33. 


\section{About the authors}

Julija Cerović, MSc, was born on the $21^{\text {st }}$ July 1982 in Podgorica. She is a teaching assistant at the Faculty of Economics in Podgorica (University of Montenegro), where she teaches Statistics, Mathematics, Business Mathematics and Financial Mathematics. Her main research areas are Financial Econometrics, Statistics and Multivariate Analysis. Insofar, Julija has published many papers in academic journals and participated in conferences in her area of interest. Author can be contacted at julija@ac.me

Milena Lipovina-Božović, PhD, was born on the $10^{\text {th }}$ April 1983 in Cetinje. She is employed at the Faculty of Economics in Podgorica (University of Montenegro) since 2005, and until today she has been teaching Mathematics, Statistics, Business Mathematics and Statistics, Macroeconomic accounts and models. Her main research areas are Applied Econometrics, Time series analysis and forecasting and Macroeconomic modelling. Milena has published many papers and participated in some very significant conferences in her area of interest. Author can be contacted at milena@ac.me

Saša Vujošević, PhD, was born on the 20 2 th March 1967 in Belgrade. He is an associate professor at the Faculty of Economics in Podgorica (University of Montenegro) where he teaches Mathematics, Business Mathematics, Financial Mathematics, Software tools, Technology and innovation and Economic forecasting. He has published many papers and participated in some very significant conferences in his area of interest. $\mathrm{He}$ is a co-author of published book "Mathematics for Economists". Author can be contacted at vsasa@ac.me 